\title{
KARAKTERISRIK KRISTAL DAN OPTIK NANOPARTIKEL ZINC OXIDE: KAJIAN EFEK MOLARITAS DALAM PROSES HIDROTHERMAL
}

\author{
Togar Saragi ${ }^{1 \mathrm{a})}$, Yonatan R Purba ${ }^{1, \mathrm{~b})}$, Satria Auffa D U ${ }^{1, \mathrm{c})}$, Maria Oktaviani ${ }^{1, \mathrm{~d})}$, \\ Edward Simanjuntak ${ }^{2, \mathrm{e})}$, Tuti Susilawati ${ }^{1, \mathrm{ff}}$, Norman Syakir ${ }^{1, \mathrm{~g})}$, \\ Mariah Kartawidjaja $^{1, \mathrm{~h})}$, Risdiana ${ }^{1, \mathrm{i})}$, Ayi Bahtiar ${ }^{1, \mathrm{j})}$
}

${ }^{1}$ Departemen Fisika Universitas Padjadjaran, Jl, Raya Bandung Sumedang Km. 21, Jatinangor 45363

${ }^{2}$ Politeknik Negeri Bandung, Jl. Gegerkalong Hilir, Ds. Ciwaruga Kotak Pos 1234 Bandung 40012

Email: a)t.saragi@phys.unpad.ac.id, ${ }^{b}$ purbayonatan@yahoo.co.id, ${ }^{c}$ auffas@gmail.com, d)mar.oktaviani@gmail.com, ${ }^{\mathrm{e})}$ yonasturboutama@ymail.com, ${ }^{\mathrm{f})}$ t.susilawati@phys.unpad.ac.id, $\left.{ }^{\mathrm{g}}\right)$ n.sjakir@phys.unpad.ac.id, h)mariah@phys.unpad.ac.id, i) risdiana@phys.unpad.ac.id, j)ayi.bahtiar@phys.unpad.ac.id

\begin{abstract}
Abstrak
Sintesis nanopartikel Zinc Oxide $(\mathrm{ZnO})$ dengan metode hidrothermal sangat dipengaruhi oleh beberapa parameter, salah satu diantaranya adalah perbandingan prekursor dan katalis dalam pelarut. Dalam penelitian ini telah berhasil disintesis nanopartikel zinc oxide dengan metode hidrothermal. Prekursor yang digunakan adalah zinc acetat dan katalis $\mathrm{NaOH}$ dalam pelarut ethanol. Perbandingan molaritas prekursor dan katalis adalah 0,008:0,5 dan 0,3:0,9. Karakteristik optik, morfologi dan struktur kristal nanopartikel $\mathrm{ZnO}$ masing-masing dilakukan dengan pengukuran UV-Vis, TEM dan XRD. Nanopartikel yang dihasilkan memiliki memiliki struktur kristal hexagonal wurtzite. Nanopartikel zinc oxide dengan perbandingan 0,3:0,9 memiliki karakteristik yang paling baik dibandingkan dengan nanopartikel dengan perbandingan 0,008:0,5. Reaksi dalam hidrothermal kaitannya dengan perubahan tekanan akibat peningkatan volume akan dikaji lebih jauh.
\end{abstract}

Kata-kata kunci: oksidasi zinc, nanopartikel, hidrotermal, molaritas

\begin{abstract}
Synthesis of Zinc Oxide $(\mathrm{ZnO})$ nanoparticles by hydrothermal method is influenced by several parameters one of them is the ratio of the precursor and catalyst in a solvent. In this study, we have successfully synthesized of zinc oxide nanoparticles by hydrothermal method. The raw material of precursor is zinc acetate, $\mathrm{NaOH}$ as catalyst and ethanol as a solvent. The molarity ratio of precursor and catalyst are 0.008: 0.5 and 0.3: 0.9. The optical characteristics, morphology and crystal structure of $\mathrm{ZnO}$ nanoparticles were characterised by the UV-Vis, TEM and XRD, respectively. From XRD measurement, it was observed that samples have hexagonal wurtzite structure and all peaks are well fitted with JCPDS:36-1451 data. The growth condition in the ratio of 0.3: 0.9 showed the best sample with high quality crystal structure and rod form. The effect of molar ratio to the characteristics of nanoparticle will be studied further in relation with the change of volume, and pressure inside of the reactor.
\end{abstract}

Keywords: zinc oxide, nanoparticle, hidrotermal, molaritas 


\section{PENDAHULUAN}

Penelitian bahan semikonduktor seperti GaAs, $\mathrm{SiC}, \mathrm{GaN}$ dan $\mathrm{ZnO}$ terus mengalami perkembangan yang pesat setelah bahan silikon ( $\mathrm{Si}$ ) tidak dapat dimanfaatkan sebagai bahan dasar divais optoelektronik. Dari berbagai jenis bahan semikonduktor tersebut Zinc Oxide ( $\mathrm{ZnO})$ merupakan bahan yang sangat potensial sebagai pengganti bahan semikonduktor generasi kedua dalam aplikasi elektronik, optoelektronik dan teknologi laser [1,2,3]. Hal ini berkaitan dengan beberapa faktor, diantaranya: memiliki band gap yang cukup lebar sekitar 3,37 eV pada suhu ruang, energi ikatan eksiton yang besar sekitar $60 \mathrm{meV}$, jauh lebih besar bila dibandingkan dengan energi ikatan eksiton $\mathrm{GaN}$ yang hanya sekitar $21 \mathrm{meV}$. Karakteristik optik ini mampu menghasilkan emisi eksiton pada panjang gelombang daerah ultraviolet berefisiensi tinggi pada suhu ruang. Disamping itu, $\mathrm{ZnO}$ memiliki stabilitas kimiawi, stabilitas termal dan stabilitas mekanik yang tinggi berkaitan dengan titik leleh yang cukup tinggi $\left(1975^{\circ} \mathrm{C}\right)$ [4].

Secara umum sintesis nanopartikel dapat dilakukan dengan dua metode, yaitu metode topdown dan metode bottom-up. Salah satu metode bottom-up yang dilakukan dalam paper ini adalah metode hidrotermal [5,6]. Proses hidrotermal terjadi pada suhu dan tekanan tertentu, sehingga kecepatan reaksi meningkat sehubungan dengan meningkatnya solubilitas bahan dalam reaktor.

Sintesis hydrothermal adalah sebuah proses pembentukan kristal bahan keramik melalui reaksi fase tunggal atau heterogen dalam sebuah media cairan pada suhu $\left(\mathrm{T}>25^{\circ} \mathrm{C}\right)$ dan tekanan $(\mathrm{P}>$ $100 \mathrm{kPa}$ ). Ketika sebuah pelarut (dan zat terlarut) dipanaskan, maka proses sintesis berlangsung pada tekanan saturasi uap tersebut pada suhu dan komposisi larutan. Beberapa keuntungan metode hydrothermal dibandingkan dengan teknologi lain dalam preparasi serbuk nanopartikel adalah: (a) nanopartikel langsung terbentuk dari larutan, (b) bahan yang terbentuk berupa anhydrous, kristal atau amorph, tergantung pada temperatur, (c) kontrol ukuran partikel melalui suhu hydrothermal, (d) kontrol bentuk partikel dari prekursor awal, (e) kontrol stoikiometri kimiawi, (f) bahan yang dihasilkan sangat reaktif saat proses sintering, (g) dalam kebanyakan kasus serbuk yang dihasilkan tidak memerlukan proses penggerusan dan kalsinasi, (h) proses sintesis dapat dilakukan pada suhu rendah, (i) selain preparasi bahan anorganik dapat juga digunakan untuk preparasi composit dan hibrid: campuran antara organik dan anorganik, (j) dapat digunakan untuk preparasi bahan yang memiliki tekanan uap yang tinggi [7].

Faktor penting yang diperhatikan dalam disain sintesis nanopartikel dengan metode hidrothermal adalah komposisi bahan dan katalis yang berdampak pada volume total reaktor (pelarut, prekursor dan katalis) dan sisa ruang kosong dalam reaktor sehingga diperoleh tekanan yang optimum selama proses reaksi pada suhu tertentu. Penentuan volume pelarut dapat dilakukan berdasarkan persamaan berikut:

$$
\text { vol }_{\text {pelarut }}(c c)=\frac{m(g r)}{\operatorname{Mr}\left(\frac{g r}{m o l}\right)} \times \frac{1000}{\text { Molar }\left(\frac{m o l}{\sigma r}\right)}
$$

dimana $m$ dan $M r$ adalah masing-masing massa (gr) dan berat molekul (gr/mol) zat terlarut. Dalam penelitian ini, prekursor yang digunakan adalah zinc asetat dihidrat, pelarut ethanol dan katalis $\mathrm{NaOH}$. Dalam penelitian sebelumnya telah dilakukan sintesis nanopartikel $\mathrm{ZnO}$ dengan perbandingan molar zinc asetat dihidrat $: \mathrm{NaOH}=1: 3$ (zinc asetat dihidrat $=0,3 \mathrm{M}$, dan $\mathrm{NaOH}=0,9$ M) dengan volume total $16,91 \mathrm{cc}$ [8]. Untuk mengamati efek tekanan selama proses hidrothermal melalui perubahan volume total reaktor, maka dalam paper ini dilakukan variasi molaritas antara zinc asetat dihidrat dan $\mathrm{NaOH}$. Molaritas zinc asetat dihidrat dipilih sebesar $0,008 \mathrm{M}$ dan molaritas $\mathrm{NaOH}$ dipilih sebesar $0,5 \mathrm{M}$. Hal ini dilakukan dengan memperhatikan beberapa pertimbangan antara lain: (1) volume total masih dibawah tiga perempat volume reaktor, (2) untuk bahan organik, massa maksimum prekursor dalam reaktor dengan volume $100 \mathrm{~mL}$ adalah 0,4 gram, sedangkan untuk bahan anorganik memiliki massa maksimum 4 gram (10 kali lebih besar dibandingkan dengan bahan organik). 


\section{METODE PENELITIAN}

Beberapa bahan yang digunakan adalah zinc acetate dehydrate $\left(\mathrm{C}_{4} \mathrm{H}_{6} \mathrm{O}_{4} \mathrm{Zn} \cdot 2 \mathrm{H}_{2} \mathrm{O}\right)$, sodium hydroxide $(\mathrm{NaOH})$, ethanol (ethyl alcohol) $\left(\mathrm{CH}_{3} \mathrm{CH}_{2} \mathrm{OH}\right)$ dan $n$-hexane. Perbandingan molaritas, massa zat terlarut, katalis dan volume pelarut dalam dilihat dalam TABEL 1.

TABEL 1. Perbandingan molaritas, massa zat terlarut, katalis dan volume pelarut.

\begin{tabular}{|c|c|c|c|c|}
\hline No & Bahan & $\begin{array}{c}\text { Molar } \\
\text { (M) }\end{array}$ & $\begin{array}{c}\text { Massa } \\
\text { (gr) }\end{array}$ & $\begin{array}{c}\text { Volume } \\
\text { (cc) }\end{array}$ \\
\hline \multirow{2}{*}{1} & $\mathrm{C}_{4} \mathrm{H}_{6} \mathrm{O}_{4} \mathrm{Zn} \cdot 2 \mathrm{H}_{2} \mathrm{O}$ & 0,3 & 0,2 & 14,5 \\
\cline { 2 - 5 } & $\mathrm{NaOH}$ & 0,9 & 0,1 & 2,41 \\
\hline \multirow{2}{*}{2} & $\mathrm{C}_{4} \mathrm{H}_{6} \mathrm{O}_{4} \mathrm{Zn} \cdot 2 \mathrm{H}_{2} \mathrm{O}$ & 0,008 & 0,070 & 40 \\
\cline { 2 - 5 } & $\mathrm{NaOH}$ & 0,5 & 0,4 & 20 \\
\hline
\end{tabular}

Nanopartikel $\mathrm{ZnO}$ disintesis pada $\mathrm{pH} 10$, suhu $100^{\circ} \mathrm{C}$ selama $5 \mathrm{jam}$. Bahan zinc acetate dehydrate dilarutkan dalam ethanol (Larutan I), dan bahan $\mathrm{NaOH}$ dilarutkan dalam ethanol (Larutan II). Larutan II diteteskan ke dalam reaktor yang berisi larutan I hingga $\mathrm{pH}$ mencapai 10 dan diaduk selama 15 menit. Reaktor dimasukkan ke dalam furnace dan dipanaskan pada suhu $100{ }^{\circ} \mathrm{C}$ selama 5 jam, dan didinginkan hingga mencapai suhu ruang. Endapan yang terbentuk, kemudian dicuci dengan menggunakan $n$-hexane, diikuti dengan proses sentrifugasi. Nanopartikel yang terbentuk diredisperse dalam ethanol dan dilakukan pengukuran UV-VIS dan TEM. Selanjutnya, nano partikel disintering pada suhu $150^{\circ} \mathrm{C}$ selama 0,5 jam dan dikarakterisasi dengan pengukuran X-Ray Diffraction (XRD).

\section{HASIL DAN PEMBAHASAN}

Hasil pengukuran UV-VIS dapat dilihat pada GAMBAR 1.

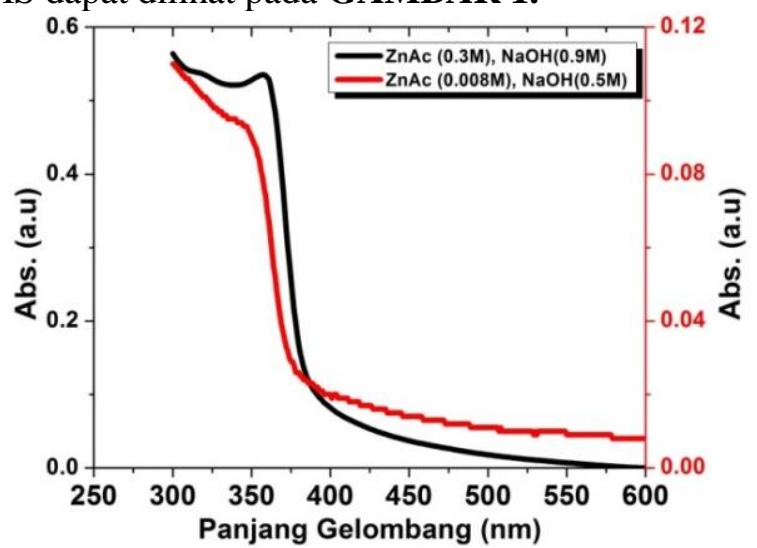

GAMBAR 1. Kurva absorbansi nanopartikel $\mathrm{ZnO}$ dengan variasi molar yang disintesis dengan metode hidrothermal pada $\mathrm{pH}=10$, suhu $100^{\circ} \mathrm{C}$ selama 5 jam.

Dari hasil perhitungan dengan menggunakan persamaan $E_{g}=1240 \times 10^{-9} / \lambda_{\text {eutoff }}(\mathrm{nm})$, diperoleh band-gap nanopartikel $\mathrm{ZnO}$ sampel 1 (perbandingan molar 0,3:0,9) sebesar 3,23 eV, dan band gap nanopartikel $\mathrm{ZnO}$ sampel 2 (perbandingan molar 0,008:0,5) sebesar 3,27 eV. Secara kuatitatif band gap kedua sample ini tidak memiliki perbedaan yang signifikan. Hal ini mengindikasikan bahwa nanopartikel yang terbentuk mendekati homogenitas yang baik. Nilai bandgap yang diperoleh dalam penelitian ini hampir sama dengan band-gap yang diperoleh oleh $\mathrm{K}$. $\mathrm{L}$. Foo, yaitu sebesar 3,25 sampai dengan 3,28 eV [6]. 


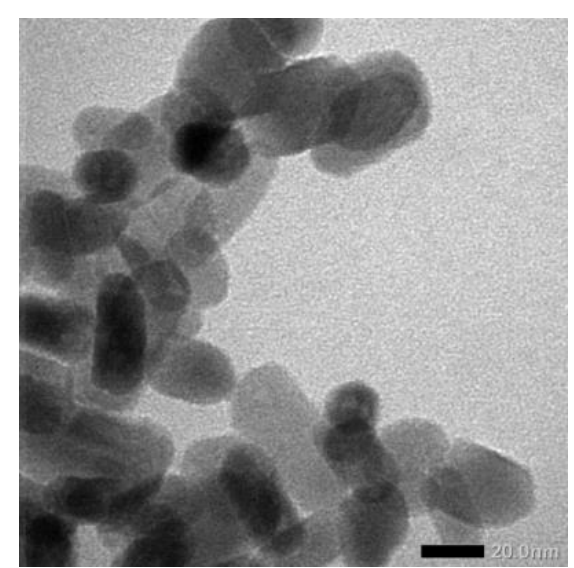

(a)

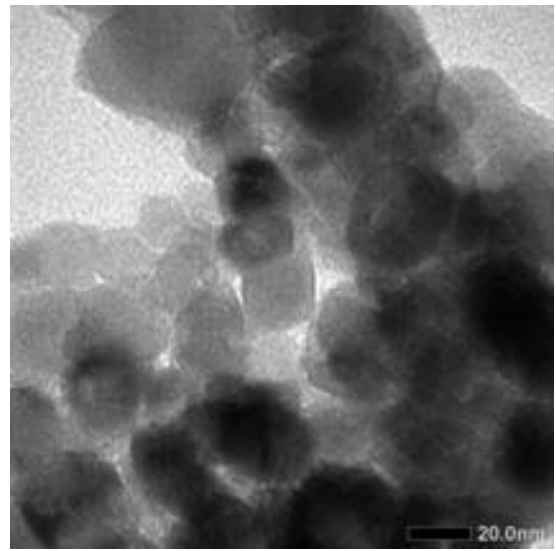

(b)

GAMBAR 2. Hasil pengukuran TEM nanopartikel $\mathrm{ZnO}$ dengan variasi molar yang disintesis dengan metode hidrothermal pada suhu $100^{\circ} \mathrm{C} \times 5 \mathrm{jam}, \mathrm{pH}=10$. (a). sampel 1 , molaritas $\mathrm{ZnAc}(0.3 \mathrm{M})$ dan $\mathrm{NaOH}(0.9 \mathrm{M})$, dan (b). sampel 2, molaritas $\mathrm{ZnAc}(0.008 \mathrm{M})$ dan $\mathrm{NaOH}(0.5 \mathrm{M})$.

Hasil pengukuran TEM sampel nanopartikel ZnO dapat dilihat pada GAMBAR 2. Dari hasil pengukuran TEM dapat dilihat bahwa nanopartikel sampel 1 lebih cenderung memiliki morfologi nanorod dengan dimensi $15 \mathrm{~nm} \times 21 \mathrm{~nm}$, sedangkan sampel 2 memiliki morfologi kubus dengan ukuran $20 \mathrm{~nm} \times 20 \mathrm{~nm}$. Secara keseluruhan hasil pengukuran TEM menghasilkan nanopartikel yang lebih homogen.

Hasil pengukuran XRD sampel nanopartikel ZnO dapat dilihat pada GAMBAR 3. Secara umum, pola XRD nanopartikel ZnO bersesuaian dengan data JCPDS 36-1451. Pola XRD menunjukkan bahwa nanopartikel yang terbentuk memiliki fase polikristalin denngan struktur hexagonal wurtzite. Sampel dengan perbandingan molar 0,008 : 0,5 memiliki pola XRD yang lebih amorph dibandingkan dengan sampel pada perbandingan molar $0,3: 0,9$. Hal ini menunjukkan bahwa proses pembentukan kristal pada perbandingan molar 0,008:0,5 lebih lambat dibandingkan dengan pada 0,3:0,9.

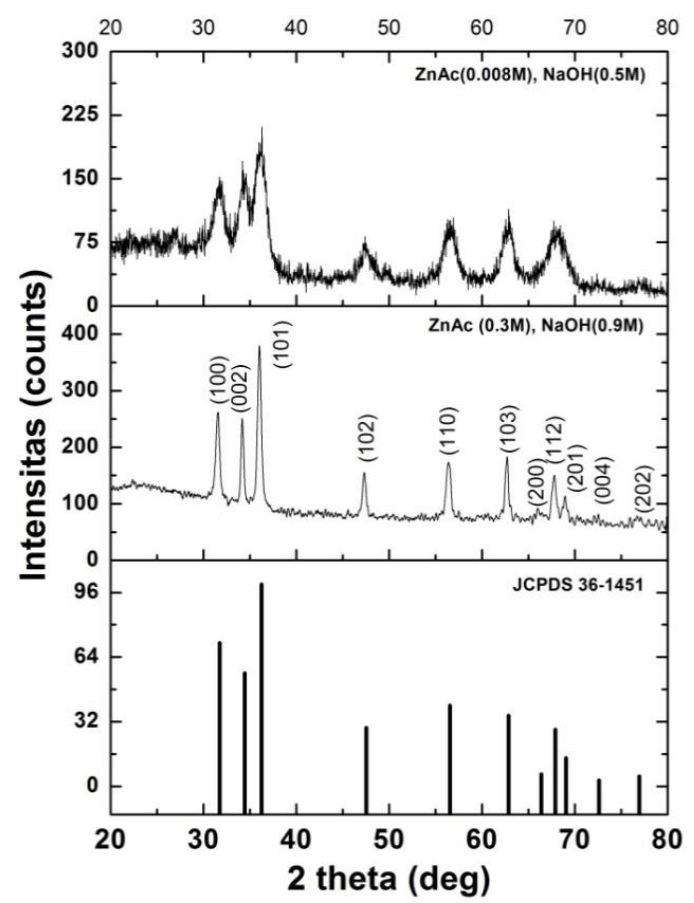

GAMBAR 3. Grafik XRD nanopartikel $\mathrm{ZnO}$ dengan variasi molar yang disintesis dengan metode hidrothermal pada suhu $100^{\circ} \mathrm{C} \times 5$ jam, $\mathrm{pH}=10$. 
Hal ini dapat dianalisa dari segi volume total pelarut dan zat terlarut dalam reaktor hidrothermal. Berdasarkan TABEL 1 dapat dilihat bahwa molaritas zinc acetate sebesar 0,3 $\mathrm{M}$ dengan volume total $16,91 \mathrm{cc}$ yang jauh lebih kecil dibandingkan dengan molaritas zinc acetate sebesar 0,008 $\mathrm{M}$ dengan volume total $60 \mathrm{cc}$. Volume total pada perbandingan molar 0,008:0,5 adalah $60 \mathrm{cc}$ (melebihi 50\% kapasitas reaktor hidrothermal), sedangkan volume total pada perbandingan molar 0,3:0,9 adalah 16,91 cc (hanya mengisi sekitar $17 \%$ volume reaktor hidrothermal). Volume ini akan menyisakan ruang reaksi yang semakin kecil, yang berdampak pada pengurangan tekanan dalam reaktor hingga penurunan solubilitas bahan $\mathrm{ZnO}$. Proses pembentukan kristal nanopartikel $\mathrm{ZnO}$ melalui reaksi fase tunggal atau heterogen dalam pelarut ethanol pada suhu $\left(\mathrm{T}=100^{\circ} \mathrm{C}\right)$ dan komposisi larutan di atas, tidak maksimum oleh karena rendahnya tekanan saturasi uap yang dimiliki.

Pola XRD yang dihasilkan dalam penelitian ini, masih lebih baik jika dibandingkan dengan hasil yang dilaporkan oleh Kl. Foo, dkk. [6]. Intensitas puncak (101) lebih tinggi dibandingkan dengan intensitas puncak (002) dan bersesuaian dengan data JCPDS, sedangkan dalam penelitian K.L. Foo, dkk., diperoleh bahwa intensitas puncak (002) lebih tinggi dibandingkan dengan intensitas puncak (101).

\section{SIMPULAN}

Nanopartikel $\mathrm{ZnO}$ yang disintesis pada $\mathrm{pH}=10$, suhu $100^{\circ} \mathrm{C}$ selama 5 jam dengan perbandingan molar 0,3:0,9 memiliki karakteristik yang lebih baik dibandingkan dengan sampel pada perbandingan 0,008:0,5. Secara umum nanopartikel $\mathrm{ZnO}$ memiliki fase polikristalin denngan struktur hexagonal wurtzite. Perbedaan kualitas kristal nanopartikel yang dihasilkan diakibatkan oleh adanya perbedaan volume total bahan dan pelarut dalam reaktor, sehingga solubilitas bahan akan berkurang terhadap penurunan tekanan uap saturasi.

\section{UCAPAN TERIMAKASIH}

Terimakasih kepada Universitas Padjadjaran, Fakultas Matematika dan Ilmu Pengetahuan Alam (FMIPA) dan Departemen Fisika FMIPA Unpad Bandung.

\section{DAFTAR ACUAN}

[1]. Bacaksiz E, Parlak M, Tomakin M, Özcelik A, Karakiz M, and Altunbas M. The effect of zinc nitrate, zinc acetate and zinc chloride precursors on investigation of structural and optical properties of $\mathrm{ZnO}$ thin films. J. Alloy. Compd. 466 (2008), p. 447-450.

[2]. Wang J, Cao J, Fang B, Lu P, Deng S and Wang H. Synthesis and characterization of multipod, flower-like, and shuttle-like $\mathrm{ZnO}$ frameworks in ionic liquids. Mater. Lett. 59 (2005), p. $1405-1408$.

[3]. Mohammad Vaseem, Ahmad Umar, Yoon-Bong Hahn, Metal Oxide Nanostructures and Their Applications, Texas, American Scientific Publishers, 2010, p. 1-36

[4]. M. D. McCluskey, S. D. Jokela, Defect in ZnO, Journal of Applied Physics, 106 (2009), p. 113.

[5]. Agnieszka Kołodziejczak-Radzimska and Teofil Jesionowski. Zinc Oxide-From Synthesis to Application: A Review. Materials. 7(2014), p. 2833-2881.

[6]. K.L. Foon, M.Kashif,U.Hashim,Wei-WenLiu, Effect of different solvents on the structural and optical properties of zinc oxide thin films for optoelectronic applications. Ceramics International. 40(2014), p. 753-761.

[7]. Dawson W J 1988, Hydrothermal synthesis of advanced ceramic powders Am. Ceram. Soc. Bull., Vol. 67, No. 10, pp. 1673-1678, 1988 
[8]. T. Saragi, M. Oktaviani, Y.R. Purba, S. A Dhiya U, Risdiana, A. Bahtiar, Kontrol ukuran kristal nanopartikel $\mathrm{ZnO}$ yang disintesis dengan metode hidrotermal, Prosiding Pertemuan Ilmiah XXIX HFI Jateng \& DIY, 25 April 2015, p. 219-221. 